\title{
The Rostral Agranular Insular Cortex, a New Site of Oxytocin to Induce Antinociception
}

\author{
Mohammed Gamal-Eltrabily, Antonio Espinosa de los Monteros-Zúñiga, Alfredo Manzano-García, \\ Guadalupe Martínez-Lorenzana, Miguel Condés-Lara, and ${ }^{\circledR}$ Abimael González-Hernández \\ Instituto de Neurobiología, Universidad Nacional Autónoma de México, Campus UNAM-Juriquilla, Juriquilla, CP 76230, Mexico
}

The rostral agranular insular cortex (RAIC) is a relevant structure in nociception. Indeed, recruitment of GABAergic activity in RAIC promotes the disinhibition of the locus ceruleus, which in turn inhibits (by noradrenergic action) the peripheral nociceptive input at the spinal cord level. In this regard, at the cortical level, oxytocin can modulate the GABAergic transmission; consequently, an interaction modulating nociception could exist between oxytocin and GABA at RAIC. Here, we tested in male Wistar rats the effect of oxytocin microinjection into RAIC during an inflammatory (by subcutaneous peripheral injection of formalin) nociceptive input. Oxytocin microinjection produces a diminution of (1) flinches induced by formalin and (2) spontaneous firing of spinal wide dynamic range cells. The above antinociceptive effect was abolished by microinjection (at RAIC) of the following: (1) L-368899 (an oxytocin receptor [OTR] antagonist) or by (2) bicuculline (a preferent $\mathrm{GABA}_{\mathrm{A}}$ receptor blocker), suggesting a GABAergic activation induced by OTR. Since intrathecal injection of an $\alpha_{2 \mathrm{~A}}$-adrenoceptor antagonist (BRL 44408) partially reversed the oxytocin effect, a descending noradrenergic antinociception is suggested. Further, injection of L-368899 per se induces a pronociceptive behavioral effect, suggesting a tonic endogenous oxytocin release during inflammatory nociceptive input. Accordingly, we found bilateral projections from the paraventricular nucleus of the hypothalamus (PVN) to RAIC. Some of the PVN-projecting cells are oxytocinergic and destinate GABAergic and OTRexpressing cells inside RAIC. Aside from the direct anatomic link between PVN and RAIC, our findings provide evidence about the role of oxytocinergic mechanisms modulating the pain process at the RAIC level.

Key words: descending pain modulation; insular cortex; oxytocin; pain; paraventricular hypothalamic nucleus; wide dynamic range cells

Significance Statement

Oxytocin is a neuropeptide involved in several functions ranging from lactation to social attachment. Over the years, the role of this molecule in pain processing has emerged, showing that, at the spinal level, oxytocin blocks pain transmission. The present work suggests that oxytocin also modulates pain at the cortical insular level by favoring cortical GABAergic transmission and activating descending spinal noradrenergic mechanisms. Indeed, we show that the paraventricular hypothalamic nucleus sends direct oxytocinergic projections to the rostral agranular insular cortex on GABAergic and oxytocin receptorexpressing neurons. Together, our data support the notion that the oxytocinergic system could act as an orchestrator of pain modulation.

\section{Introduction}

The rostral agranular insular cortex (RAIC) has multiple connections with pain-related brain areas, such as medial thalamic nuclei, ACC, infralimbic cortex, raphe magnus (RM), periaqueductal gray matter (PAG), parabrachial nucleus, and lateral hypothalamus (Jasmin et al., 2004). Although RAIC seems to have mainly a pronociceptive function because its lesion produced antinociception during neuropathic (induced by chronic

Author contributions: M.G.-E., A.E.d.I.M.-Z., A.M.-G., G.M.-L., and M.C.-L. performed research; M.G.-E., A.E.d.I.M.-Z., A.M.-G., G.M.-L., and A.G.-H. analyzed data; M.G.-E. wrote the first draft of the paper; M.G.-E., A.E.d.I.M.-Z., M.C.-L., and A.G.-H. edited the paper; G.M.-L., M.C.-L., and A.G.-H. designed research; M.G.-E., M.C.-L. and A.G.-H. wrote the paper. constriction of the sciatic nerve) or inflammatory (induced by carrageenan) pain (Coffeen et al., 2011), several reports have explored the participation of different neuromodulators in RAIC

This work was supported by PAPIIT-UNAM Mexico Grant IA203119 to A.G-H. and IN200415 to M.C.-L., Fondo Sectorial de Investigación para la Educación CONACyT-Mexico Grant A1-S-23631 to A.G.-H., and Committee for Aid and Education in Neurochemistry of the International Society for Neurochemistry. M.G.-E. is a doctoral student from Programa de Doctorado en Ciencias Biomédicas and received CONACyT-Mexico Fellowship 808245. We thank Elsa N. Hernández-Ríos for technical assistance in the Microscopy and Image Analysis Unit; Dr. Deisy Gasca-Martínez for assistance in the Behavioral Analysis Unit Facility; and Jessica González-Norris for proofreading the manuscript.

The authors declare no competing financial interests.

Correspondence should be addressed to Abimael González-Hernández at abimaelgh@comunidad.unam.mx. https://doi.org/10.1523/JNEUROSCI.0962-20.2020

Copyright $\odot 2020$ the authors 
during nociception. For example, using the formalin test and spinal dorsal horn electrophysiological experiments, Burkey et al. (1996) reported that unilateral morphine microinjection into the RAIC induced an antinociceptive effect mediated by $\mu$ - and $\kappa$-opioid receptors.

In this sense, Jasmin et al. (2003) proposed that RAIC could modulate nociception through the GABAergic activation of two different systems: (1) RAIC-locus ceruleus (LC), where $\mathrm{GABA}_{\mathrm{A}}$ receptors play the main role; and (2) RAIC-amygdala mediated by $\mathrm{GABA}_{\mathrm{B}}$ receptors. In the first case, a local increase of GABA levels in RAIC activates the $\mathrm{GABA}_{\mathrm{A}}$ receptors, diminishing the excitatory glutamatergic output to the RM and parabrachial nucleus, which are tonically inhibiting the LC; so increasing GABA levels in RAIC promote a descending noradrenergic antinociceptive effect at the spinal cord level by LC disinhibition. In this regard, it has been shown in the PFC that oxytocin increases GABA release by activation of oxytocin receptors (OTRs) (Sabihi et al., 2017). These results may suggest a probable interaction between the oxytocin and GABAergic mechanisms modulating nociception at cortical levels. Certainly, at the spinal level, oxytocin can activate GABAergic neurons, inhibiting the nociceptive transmission (see Gonzalez-Hernandez and Charlet, 2018).

Importantly, electrical stimulation of the paraventricular hypothalamic nucleus (PVN) (one of the main sites of oxytocin synthesis) induces a behavioral and electrophysiological spinal antinociception (Condés-Lara et al., 2006; Miranda-Cardenas et al., 2006; DeLaTorre et al., 2009). This PVN-induced antinociception is mainly mediated by direct oxytocinergic transmission at the spinal dorsal horn level (Miranda-Cardenas et al., 2006; Condés-Lara et al., 2009; González-Hernández et al., 2014, 2019; Eliava et al., 2016); nevertheless, since recruitment of other "antinociceptive" brain areas connected with the PVN also occurs (e.g., RM, LC, and PAG) (Pittman et al., 1981; Condés-Lara et al., 2012, 2015; Godínez-Chaparro et al., 2016), oxytocin can induce antinociception by activation of other supraspinal centers. Considering that oxytocin is a typical stress hormone that could be released under acute stressors (e.g., nociceptive stimulus) (Motojima et al., 2017) and can act centrally in different brain regions (Dumais and Veenema, 2016; Moghadam et al., 2018) by interacting with the GABAergic system (Kaneko et al., 2016; Sabihi et al., 2017; Thakur et al., 2019), we hypothesized that microinjecting oxytocin into the RAIC could induce an antinociceptive action.

Based on these data, and using behavioral, pharmacological, electrophysiological, and immunofluorescence approaches, the present study was designed to test: (1) the role of oxytocin in RAIC over nociception modulation in a model of inflammatory pain (formalin test); (2) its possible mechanism; and (3) the presence of PVN oxytocinergic innervations toward RAIC. Preliminary data have been presented previously in abstract form (Gamal-Eltrabily et al., 2019).

\section{Materials and Methods}

Animals and ethical standards

A total of 104 male Wistar rats weighing 260-310 g and taken from the Institute of Neurobiology's animal house were used in this study. Animals were housed in pairs in plastic cages with wood-based bedding under a 12:12 h light-dark cycle (lights on at 07:00 h) in a special room at constant temperature $\left(22 \pm 2^{\circ} \mathrm{C}\right)$ and humidity (50\%) with food and water ad libitum. Our Institutional Ethics Committee approved all animal procedures and protocols, which followed the Guide for the care and use of laboratory animals established by the National Institutes of Health and ARRIVE guidelines for reporting experiments involving animals
(McGrath et al., 2010). The behavioral experiments were performed between 10:00 $\mathrm{h}$ and 14:00 h. All efforts were made to limit distress and use only the number of animals necessary to produce reliable scientific data.

\section{Experimental design for behavioral experiments}

Formalin-induced nociception and drug treatments. To analyze the effect of oxytocin microinjection into RAIC on the behavioral nociception, the 5\% formalin test was used (Dubuisson and Dennis, 1977). Briefly, the rats received formalin $(50 \mu$ l, s.c.) in one hind paw, and the nocifensive behavior was quantified as the number of flinches of the injected paw during 1 min periods every $5 \mathrm{~min}$ for up to $1 \mathrm{~h}$ after injection. Flinching was characterized as a rapid and brief withdrawal of the injected paw. As previously reported, formalin-induced flinching behavior was biphasic. The initial acute phase $(0-10 \mathrm{~min})$ was followed by a prolonged persistent response (15-60 $\mathrm{min}$ ).

Before the formalin test, the animals were placed in open Plexiglas observation chambers for $1 \mathrm{~h}$ during 3 consecutive days to allow them to become familiar with their surroundings. On the fourth day, before the formalin injection, the animals were anesthetized with sevoflurane (8\% in a mixture of $75 \% \mathrm{~N}_{2} \mathrm{O} / 25 \% \mathrm{O}_{2}$ ) delivered through a vaporizer. Once the animals were unconscious, they were mounted onto a stereotaxic frame (Kopf Instruments) and maintained under 6\% sevoflurane using a special mask throughout the surgical procedure (20-25 min). The skull was exposed, and a small trephine hole was drilled. Under this condition, a glass micropipette coupled to a $1 \mu \mathrm{l}$ Hamilton syringe was introduced into RAIC (AP: bregma 2.2-2.7 mm; L: 4.5-5.0 mm; H: 5.2-5.8 mm; accordingly to Paxinos and Watson, 2006). The glass micropipettes (Corning 7740) were pulled using the horizontal Flaming/Brown Micropipette P-97 puller (Sutter Instruments), allowing us to have a diameter tip of $\sim 10 \mu \mathrm{m}$. Furthermore, the Hamilton syringe was connected to a vernier to control the volume to inject in the RAIC. At this point, the animals were divided into three main groups $(N=24, N=24$, and $N=18$ ), and the microinjection procedure was performed.

The first group $(N=24)$ was divided into four subgroups ( $n=6$ each) as follows: (1) sham procedure (surgical procedure without injection into RAIC); (2) vehicle subgroup, where $40 \mathrm{nl}$ of isotonic saline solution $(0.9 \% \mathrm{NaCl})$ was microinjected into RAIC; (3) 40 pmol oxytocin microinjected into RAIC; and (4) $400 \mathrm{pmol}$ oxytocin microinjected into RAIC.

The second group $(N=24)$ was divided into four subgroups $(n=6$ each), and we evaluated the role of OTR, GABA channels, and $\alpha_{2 A^{-}}$ adrenoceptors in the $400 \mathrm{pmol}$ oxytocin-induced antinociception. In this case, the antagonists were given $10 \mathrm{~min}$ before oxytocin. Hence, (1) 400 pmol (2S)-2-amino-N- [(1S,2S,4R)-7,7-dimethyl-1-[[[(4-(2-methylphenyl)-piperazinyl] sulfonyl)methyl]bicyclo-[2.2.1]hept-2-yl]-4-(methylsulfonyl)-butanamide hydrochloride (L-368899, OTR antagonist) or (2) 200 pmol bicuculline (a preferent $\mathrm{GABA}_{\mathrm{A}}$ receptor antagonist) was microinjected into RAIC, (3) whereas (2) 2-[2H-(1-methyl-1,3-dihydroinindole) methyl]-4,5-dihydro-imidazole maleate (BRL 44408, $\alpha_{2 \mathrm{~A}}$-adrenoeptor antagonist; $1 \mathrm{nmol}$ ) was intrathecally injected. In this set of experiments, the animals received two RAIC microinjections; thus, we also analyzed the effect of (4) two microinjections of saline solution $(0.9 \% \mathrm{NaCl}$; vehicle subgroup) on the flinching behavior.

The third group $(N=18)$ was divided in three subgroups $(n=6$ each), and we analyzed the per se effect of the antagonists used: (1) 400 pmol L-368899 in RAIC, (2) 200 pmol bicuculline in RAIC, and (3) $1 \mathrm{nmol}$ BRL 44408 at spinal lumbar level.

After RAIC microinjection, the micropipette was removed, the bone trephine was closed with bone wax, and the cut was closed by stitches and local infiltration of $10 \%$ lidocaine $(100 \mu \mathrm{l})$. Immediately after, the animals were allocated to their chambers. Ten minutes after recovery from anesthesia, the rats underwent the formalin test (see Fig. 1A).

In all cases, a $40 \mathrm{nl}$ volume was microinjected into RAIC per treatment, and the injections were given contralaterally to the subcutaneous formalin injection. At this point, we must emphasize that, to our knowledge, the method described here to perform microinjection before a behavioral test has not been previously reported. BRL 44408 was given intrathecally at a volume of $10 \mu \mathrm{l}$ by a direct lumbar puncture as previously described by Mestre et al. (1994). Briefly, a 22 G needle connected 

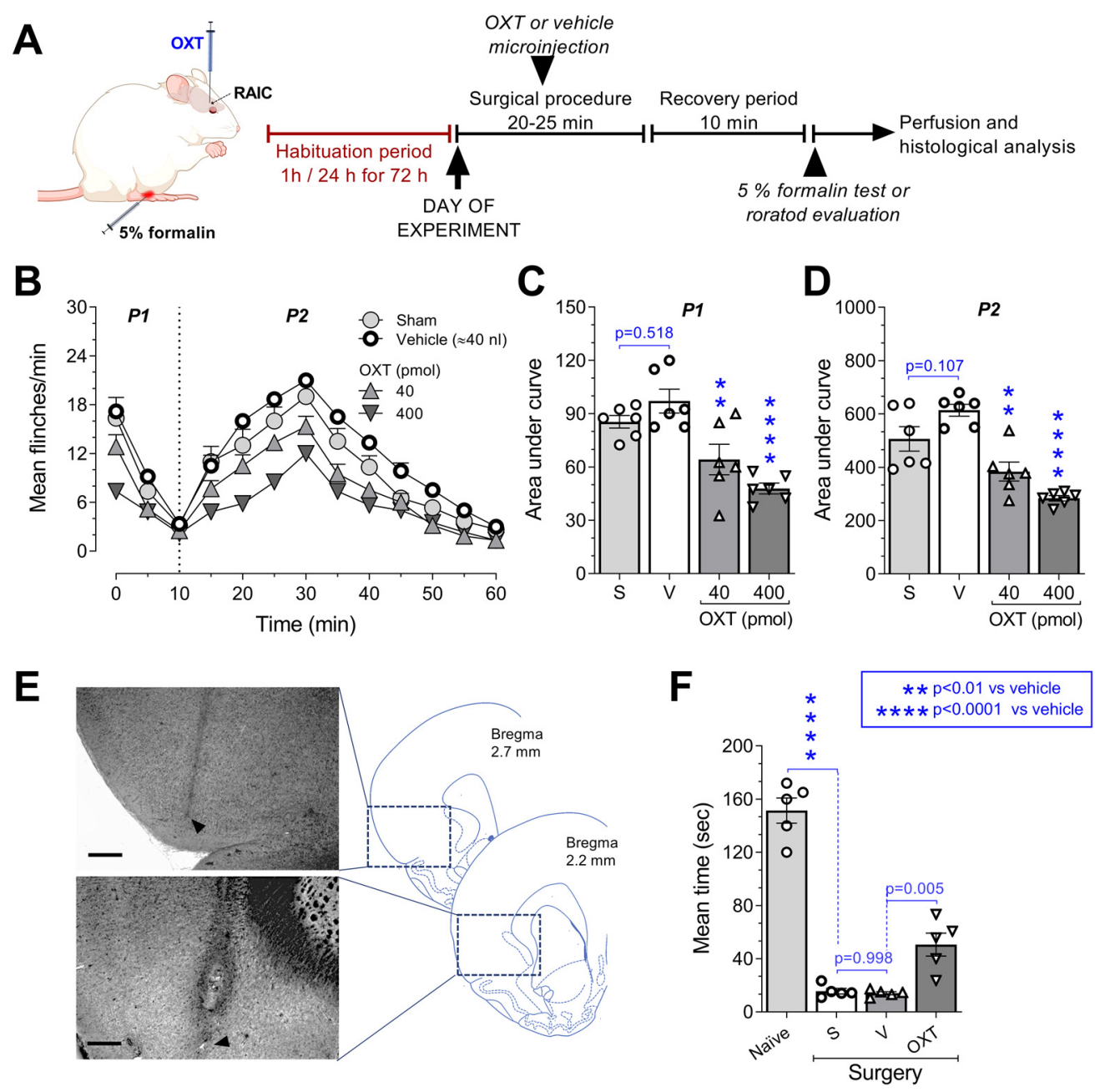

Figure 1. Oxytocin (OXT) microinjection in the RAIC produces antinociception. $A$, Diagram and timeline schema of the experimental design used in the behavioral studies (5\% formalin test and rotarod evaluation). $\boldsymbol{B}$, Time course during Phase I (P1) and Phase II (P2) of the mean number of flinches observed after OXT microinjection into RAIC ( 40 or $400 \mathrm{nmol} ; n=6$ each concentration) in rats submitted to the 5\% formalin test. OXT diminished the number of flinches. $C, D$, The time course data expressed as area under the mean number of flinches against time curve (AUC). The one-way ANOVA showed differences between treatments, suggesting that OXT reduced the AUC during P1 and P2. E, Two photomicrographs obtained by light microscope represent two examples of the microinjection sites in RAIC (AP: bregma 2.7, $2.2 \mathrm{~mm}$ ). Scale bar: both photomicrographs, $200 \mu \mathrm{m}$. $\boldsymbol{F}$, Although after surgery the time spent (seconds) on the treadmill apparatus before failing significantly diminished compared with naive animals (without any surgery or treatment), the animals that received OXT improved the time spent in the rotarod test compared with sham procedure or vehicle microinjection. For statistical details, see Table 1.

to a $25 \mu \mathrm{l}$ Hamilton syringe was used, and the intrathecal injection was performed in the L5-L6 intervertebral space.

Motor coordination test. In a group of animals $(N=20)$, we investigated a possible motor alteration induced by the oxytocin microinjection into RAIC. Briefly, a motor coordination test (rotarod test) was performed using a treadmill apparatus (IITC Life Science). Briefly, this test consists of placing the animals on a cylinder (diameter: $7 \mathrm{~cm}$ ) rotating at a constant speed of 15 revolutions per minute. Animals were trained to walk on the cylinder (cutoff time: $180 \mathrm{~s}$ ) for three sessions before the experimental day without any treatment or surgery. On the experimental day, the animals were divided into four subgroups ( $n=5$ for each subgroup), namely: (1) naive group, which had no surgical procedure; (2) sham group, which underwent the same surgical procedure as previously mentioned without any volume microinjection into RAIC; (3) vehicle group, in which $40 \mathrm{nl}$ of saline solution was microinjected into RAIC; and (4) oxytocin group, in which $400 \mathrm{pmol}$ was microinjected into RAIC. The animals were left $15 \mathrm{~min}$ for recovery; then the latency was calculated based on a three trial average for each animal.

Experimental design for in vivo electrophysiological recordings

Electrophysiological experiments were performed to analyze the effect of oxytocin micro-injection in the neuronal activity of spinal dorsal horn wide dynamic range (WDR) cells induced by a peripheral nociceptive stimulus (subcutaneous injection of $50 \mu \mathrm{l}$ of $1 \%$ formalin).

Surgical procedures. Animals were deeply anesthetized with $8 \%$ sevoflurane (in a mixture of $75 \% \mathrm{~N}_{2} \mathrm{O} / 25 \% \mathrm{O}_{2}$ ) delivered through a vaporizer. Under these conditions, an intratracheal cannula was inserted for artificial ventilation (65-75 strokes/min) to maintain the anesthesia. Then, rats were mounted in a stereotaxic apparatus (Kopf Instruments) with a spinal cord restrained frame. To record the evoked unitary neuronal activity of the spinal WDR cells, the spinal cord was exposed at the lumbar vertebrae level to perform a laminectomy (at L2-L4 segments), and the dura was carefully removed. During the experiments, the animals were not paralyzed, and we did not observe any withdrawal reaction. Furthermore, we followed the same surgical procedure previously described to microinject oxytocin into RAIC.

The subsequent experimental protocols (see below) were performed under $2 \%-2.5 \%$ sevoflurane to achieve the ethically adequate level of anesthesia without excessively depressing neuronal responses to noxious stimuli (Condés-Lara et al., 2012). End-tidal $\mathrm{CO}_{2}$ was monitored with a $\mathrm{CO}_{2}$ analyzer (model MM206, Artema Medical) and kept between 2.5\% and $3.2 \%$. Core body temperature was maintained at $37^{\circ} \mathrm{C}$ using a circulating water pad.

Extracellular unitary recordings. Extracellular unitary activity was recorded in 12 rats (control and oxytocin-pretreated groups, $n=6$ for 
Table 1. Statistical data with their respective post hoc comparison for the behavioral and electrophysiological data ${ }^{a}$

\begin{tabular}{|c|c|c|}
\hline Figure & Test & Post hoc comparison \\
\hline 1 & Ordinary one-way ANOVA & Tukey's test \\
\hline $1 C$ & Treatment effect: $F_{(3,20)}=13.67 ; p<0.0001$ & $\begin{array}{l}\text { Surgery vs vehicle, } p=0.518 \\
\text { Vehicle vs } 40 \mathrm{nmol} 0 \mathrm{XT}, p=0.0042 \\
\text { Vehicle vs } 400 \mathrm{nmol} 0 \mathrm{XT}, p<0.0001 \\
40 \mathrm{nmol} 0 \mathrm{XT} \text { vs } 400 \mathrm{nmol} 0 \mathrm{XT}, p=0.244\end{array}$ \\
\hline $1 D$ & Treatment effect: $F_{(3,20)}=20.74 ; p<0.0001$ & $\begin{array}{l}\text { Surgery vs vehicle, } p=0.107 \\
\text { Vehicle vs } 40 \mathrm{nmol} 0 \mathrm{XT}, p=0003 \\
\text { Vehicle vs } 400 \mathrm{nmol} 0 \mathrm{XT}, p<0.0001 \\
40 \mathrm{nmol} 0 \mathrm{XT} \text { vs } 400 \mathrm{nmol} 0 \mathrm{XT}, p=0.147\end{array}$ \\
\hline $1 F$ & Treatment effect: $F_{(3,16)}=98.28 ; p<0.0001$ & $\begin{array}{l}\text { Naive vs surgery, } p<0.0001 \\
\text { Naive vs vehicle, } p<0.0001 \\
\text { Naive vs } 0 \mathrm{XT}, p<0.0001 \\
\text { Surgery vs vehicle, } p=0.998 \\
\text { OXT vs vehicle, } p=0.005 \\
\text { OXT vs surgery, } p=0.008\end{array}$ \\
\hline 3 & Nonpaired $t$ test (two-tailed) & NA \\
\hline $\begin{array}{l}3 B \\
3 C\end{array}$ & $\begin{array}{l}t_{(10)}=2.507, p=0.031 \\
t_{(10)}=3.163, p=0.010\end{array}$ & \\
\hline 6 & Ordinary one-way ANOVA & Tukey's test \\
\hline $6 C$ & Treatment effect: $F_{(4,25)}=31.21 ; p<0.0001$ & $\begin{array}{l}\text { Vehicle vs } 0 X T, p<0.0001 \\
\mathrm{~L}-368899 \text { vs } 0 X \mathrm{XT}, p<0.0001 \\
\text { Vehicle vs } \mathrm{L}-368899, p=0.0704 \\
\text { Bicuculline vs } 0 X \mathrm{XX}, p=0.0003 \\
\text { BRL } 44408 \text { vs } 0 X \mathrm{XX}, p=0.613\end{array}$ \\
\hline $6 D$ & Treatment effect: $F_{(4,25)}=295.3 ; p<0.0001$ & $\begin{array}{l}\text { Vehicle vs } 0 X T, p<0.0001 \\
\text { L-368899 vs } 0 X T, p<0.0001 \\
\text { Vehicle vs L-368899, } p<0.0001 \\
\text { Bicuculline vs } 0 X T, p<0.0001 \\
\text { BRL } 44408 \text { vs } 0 X T, p<0.0001\end{array}$ \\
\hline $6 F$ & Treatment effect: $F_{(3,20)}=7.695 ; p=0.0013$ & $\begin{array}{l}\text { Vehicle vs } L-368899, p=0.019 \\
\text { Vehicle vs bicuculline, } p=0.846 \\
\text { Vehicle vs BRL 44408, } p=0.802\end{array}$ \\
\hline $6 G$ & Treatment effect: $F_{(3,20)}=50.39 ; p<0.0001$ & $\begin{array}{l}\text { Vehicle vs L-368899, } p<0.0001 \\
\text { Vehicle vs bicuculline, } p=0.467 \\
\text { Vehicle vs BRL 44408, } p=0.299\end{array}$ \\
\hline
\end{tabular}

${ }^{a}$ OXT, Oxytocin. Significance: $p \leq 0.05$

each) with a glass micropipette ( $4-8 \mathrm{~m} \Omega$ ) filled with $4 \%$ pontamine sky blue (1 $\mathrm{M} \mathrm{KCl}$ solution). The microelectrodes were lowered (200$1200 \mu \mathrm{m}$ ) into the laminae of the spinal dorsal horn segments using a hydraulic micro-drive (David Kopf Instruments). For each recorded cell, the specific somatic receptive field $(\mathrm{RF})$ was located by tapping on the entire ipsilateral hind paw and toes; then, electrical stimulation of the RF was performed. (see Electrical stimulation of the somatic RF and drug administration).

The evoked extracellular neuronal activity was amplified $\times 1000$ (P511 series AC Pre-amplifier, Grass Instruments), digitalized, and discriminated using CED hardware and Spike2 version 5.15 software (Cambridge Electronic Design). Raw and discriminated signals were fed through an audio monitor and displayed on an oscilloscope (TDS 420A; Tektronix). Digitalized waveforms and recorded spike trains were stored on a computer disk for offline analyses. Baselines and evoked activities of the WDR cells were recorded and analyzed as follows: (1) peristimulus time histograms (PSTHs) and (2) spontaneous neuronal firing. The PSTH was used to identify incoming action potentials from $\mathrm{A} \beta(0-20$ $\mathrm{ms}), \mathrm{A} \delta(20-90 \mathrm{~ms})$, and $\mathrm{C}$ fibers $(90-350 \mathrm{~ms})$ in response to $10 \mathrm{RF}$ stimuli.

Electrical stimulation of the somatic RF and drug administration. The RF electrical stimulation was done using two fine needles (27 G) attached to a stimulus isolator unit (SIU6; Grass Instruments) inserted subcutaneously into the RF of the recorded neuron. Then, electrical test stimulation was performed (S88 Stimulator; Grass Instruments). This test consisted of 10 square-wave stimuli at $0.2 \mathrm{~Hz}$, with $1 \mathrm{~ms}$ pulse duration at $0.4-0.6 \mathrm{~mA}$ intensity required to evoke a C-fiber response. We recorded the electrophysiological responses of 12 single WDR neurons (mean depth $500 \pm 200 \mu \mathrm{m}$ ) in the control situation (two consecutive tests with no more than $\pm 10 \%$ variation).
Upon this, $50 \mu \mathrm{l}$ of $1 \%$ formalin was subcutaneously injected into the peripheral RF of the WDR cell, and $1 \mathrm{~min}$ of neuronal spontaneous activity was recorded every $5 \mathrm{~min}$ for $60 \mathrm{~min}(n=6)$. Another group of rats $(n=6)$ received an oxytocin microinjection into the contralateral RAIC $(40 \mathrm{pmol} / 40 \mathrm{nl}) 10 \mathrm{~min}$ before formalin injection, and the procedure was then continued as mentioned. Importantly, to ensure that we were recording the same WDR cell along the $60 \mathrm{~min}$, we randomly tested whether the recorded cell was still susceptible to electrical stimulation.

Histologic reconstruction of intra-RAIC injections in the behavioral and electrophysiological experiments

At the end of the behavioral and electrophysiological experiments, the animals received an overdose of pentobarbital $(45 \mathrm{mg} / \mathrm{kg})$ and were transcardially perfused with $0.9 \% \mathrm{NaCl}$, followed by $10 \%$ formaldehyde ( $\sim 200 \mathrm{ml}$ of each). Brains were postfixed in 10\% formaldehyde and cut into $40 \mu \mathrm{m}$ serial coronal sections with a freezing microtome (SM2000 $\mathrm{R}$, Leica Biosystems). The position of the electrode tip was observed with a light microscope to ensure a precise injection site into the RAIC.

\section{Neural tracing experiments}

Microinjection of the retrograde tracer Fluoro-Gold (FG) into the RAIC. The rats were anesthetized by intraperitoneal injection of ketamine plus xylazine $(70 / 6 \mathrm{mg} / \mathrm{kg})$ and mounted in a stereotaxic apparatus. Using glass micropipettes ( $\sim 10-\mu$ m-diameter tips), $20 \mathrm{nl}$ of $2 \%$ solution of retrograde tracer, hydroxystilbamidine (FG; Fluorochrome), was microinjected into RAIC $(N=3)$. Then, the surgical wounds were sutured. Each animal was kept in an individual cage for $5 \mathrm{~d}$ to allow the axonal transport from the RAIC, reanesthetized with pentobarbital 

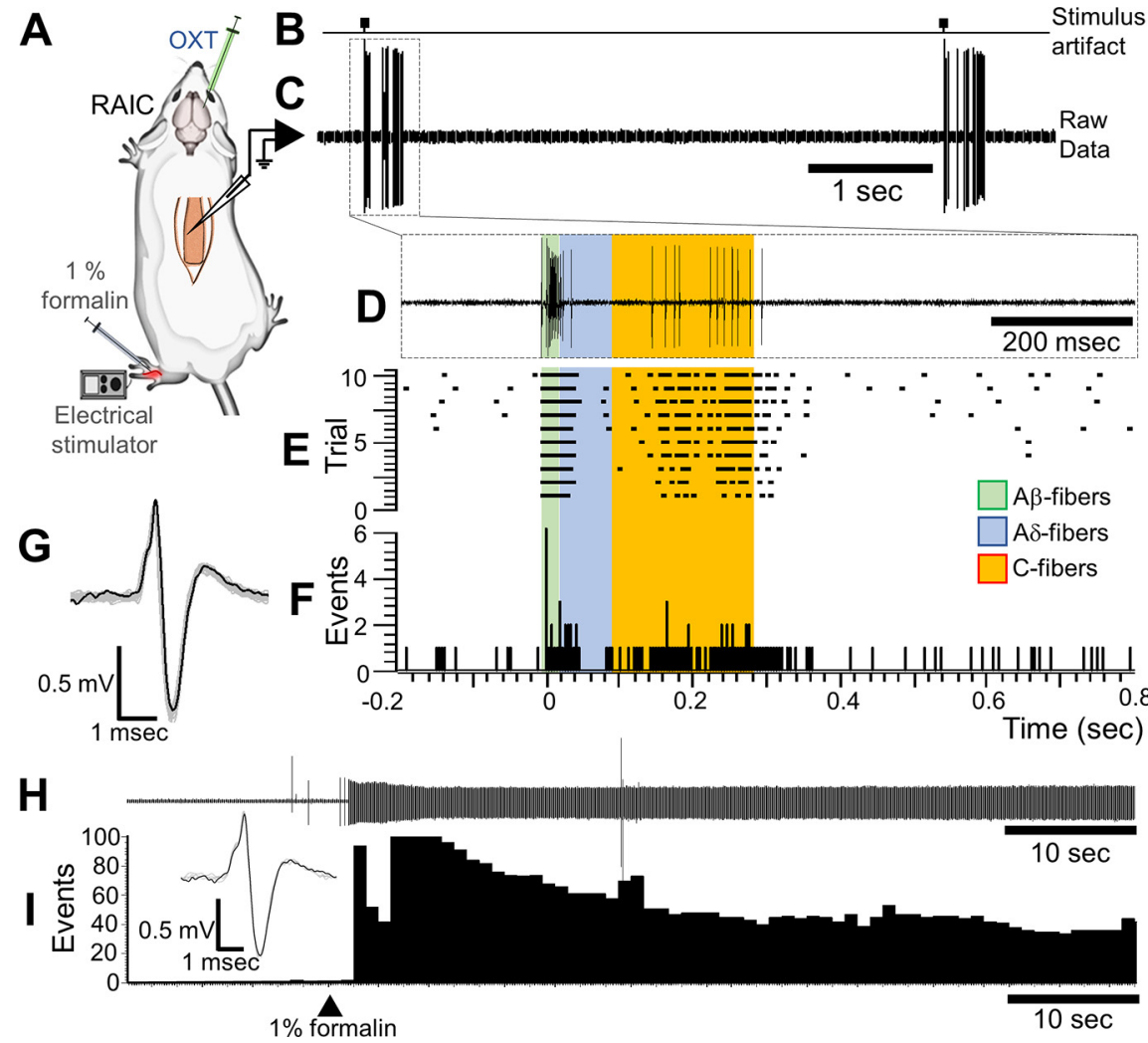

Figure 2. Spinal dorsal horn WDR cells and their response to peripheral electrical or formalin administration. $A$, Experimental setup design illustrating the electrophysiological recording of lumbar dorsal horn WDR cells and the location of the RF stimulation on the paw. OXT was microinjected in the contralateral site of the electrophysiological recording. $\boldsymbol{B}$, The raw data of two electrical stimulus artifacts. $C$, Two consecutive WDR responses to electrical RF stimulation. $\boldsymbol{D}$, Raw tracing of a single response to RF electrical stimulation. $\boldsymbol{E}, \boldsymbol{F}$, The raster plot and the PSTHs constructed from 10 WDR responses to RF electrical stimulation depicting the different fiber components ( $A \beta, A \delta$, and ( fibers). $G$, The wave average of the activity of the WDR neuron recorded is illustrated. Before RF stimulation, no spontaneous response occurs. $\boldsymbol{H}$, A raw electrophysiological record of a spinal WDR neuron before and after peripheral formalin administration ( $50 \mu \mathrm{l} \mathrm{of} \mathrm{1 \%} \mathrm{formalin)} \mathrm{in} \mathrm{its} \mathrm{RF.} \mathrm{After} \mathrm{formalin} \mathrm{injection,} \mathrm{the} \mathrm{WDR} \mathrm{cell} \mathrm{starts}$ "spontaneously" firing. I, A time histogram showing the neuron firing rate. The wave average of the activity of the recorded WDR neuron is the same as the one in $\boldsymbol{G}$.

$(45 \mathrm{mg} / \mathrm{kg})$, and perfused with isotonic saline solution $(\sim 200 \mathrm{ml})$ followed by $4 \%$ PFA in PB $0.1 \mathrm{M}(\sim 300 \mathrm{ml})$. The brain was removed and kept in the same fixative solution for $2 \mathrm{~h}$ and cryoprotected in a $30 \%$ sucrose solution. Two days later, $40-\mu \mathrm{m}$-thick coronal sections were obtained to verify the FG injection site and the FG-positive cells in the PVN.

For each injected rat, 5 series were collected, 2 series were mounted (the first for verification and the second for cresyl violet staining), and the rest were kept in $0.1 \mathrm{M}$ PB for further immunofluorescence studies (see Immunofluorescence studies).

Microinjection of the anterograde tracer Fluoro-Ruby (FR) into the $P V N$. In a group of 3 rats, $60 \mathrm{nl}$ of an anterograde tracer, FR (tetramethyl rhodamine dextran-amine; Fluorochrome), was microinjected into the PVN (AP: bregma -1.4 to 1.6 ; L: $0.5 \mathrm{~mm}$; $\mathrm{H}: 8 \mathrm{~mm}$ ). As described, the same procedures were applied, except that the rats were left for a $10 \mathrm{~d}$ recovery period. The injection site in the PVN and the FR-positive fibers inside RAIC was verified, and further immunofluorescence experiments were performed.

\section{Immunofluorescence studies}

To study the oxytocinergic nature of PVN-projecting neurons to RAIC, the PVN slices were washed with PBS $(0.1 \mathrm{M}, \mathrm{pH}$ 7.4). Later, the slices were incubated in PBS with the following primary antibodies: anti-neurophysin antibodies (PS60 mouse monoclonal, 1:250 diluted; gift from Harold Gainer, National Institutes of Health) and anti-FG (rabbit, 1:400 diluted; Fluorochrome, catalog \#52-9680) for $24 \mathrm{~h}$. On the following day, the tissue was washed using SBP for 10 min and then incubated with the secondary antibodies (from Invitrogen): (1) donkey anti-rabbit IgG (AlexaFluor-555 conjugate; catalog \#A31572) and (2) donkey anti-mouse IgG (AlexaFluor-488 conjugate; catalog \#A21202).

To investigate the relation between fibers originating from the PVN with the OTR-expressing cells and GABAergic neurons inside RAIC, the OTR in RAIC was detected using anti-OTR primary antibodies (polyclonal goat, 1:400 diluted; catalog \#sc-8103; Santa Cruz Biotechnology), whereas GABAergic neurons were identified using anti-GABA (polyclonal rabbit, 1:1500 diluted; catalog \#A2052; Sigma Millipore). The slices were incubated for $24 \mathrm{~h}$ with the primary antibodies; and subsequently, a $10 \mathrm{~min}$ wash was performed with PBS followed by incubation with secondary antibodies (from Invitrogen): (1) donkey anti-goat IgG (AlexaFluor-647 conjugate; catalog \#A-21447) and (2) donkey anti-rabbit IgG (AlexaFluor-488 conjugate; catalog \#A21026). Negative controls were done by incubation with only secondary antibodies under the same experimental conditions.

Confocal microscopy and image analysis The slices were observed under focal microscopy. Confocal images of the PVN and RAIC were acquired using an LSM 510 META confocal microscope (Carl Zeiss) with Axiovert 200 or an LSM 780 DUO confocal microscope with (Carl Zeiss) motorized stage and software version 4.2 (Carl Zeiss). The pinhole and $z$-sectioning intervals were kept constant for all images. In all cases, $\sim 25-35$ optical $z$ sections of 1 $\mu \mathrm{m}$ thickness were obtained from the 40 $\mu \mathrm{m}$-thick tissue for each image stack.

Optical sections were acquired at a digital size of $1024 \times 1024$ pixels and averaged 4 times to reduce noise. In all cases, the image obtained was improved (brightness and $\gamma$ ) and analyzed using the ZEN 2 Blue Edition Software (Carl Zeiss Microscopy). The color for each channel was selected as follows: red, oxytocin and FR; yellow, FG; green, anti-FG and GABA; and blue, OTR. In all cases, a two-dimensional projection image and a single-optical section image were imported in Tag Image File Format and were used to compose the multipaneled figures.

\section{Drugs}

Apart from the anesthetics (ketamine, xylazine, sevoflurane, and pentobarbital), this study used the following compounds: from Tocris Bioscience, (1) L-368899 hydrochloride; from Sigma Millipore, (1) oxytocin acetate salt hydrate; (2) 2-[2H-(1-methyl-1,3-dihydroinindole) methyl]-4,5-dihydro-imidazole maleate (BRL 44408); and (3) bicuculline methiodide. All drugs were dissolved in physiological saline solution $(0.9 \% \mathrm{NaCl})$. The concentration of bicuculline and BRL 44408 was chosen based on previous studies showing that these drugs are able to selectively block their respective receptors (Jasmin et al., 2003; Yoon et al., 2011).

Taking into account the current electrophysiological, behavioral, and clinical evidence (Madrazo et al., 1987; DelaTorre et al., 2009; Eliava et al., 2016; Sun et al., 2018; Taati and Tamaddonfard, 2018; GonzálezHernández et al., 2019) about the duration of antinociceptive action of oxytocin, we decided to microinject this neuropeptide between 10 and 20 min before the test. 

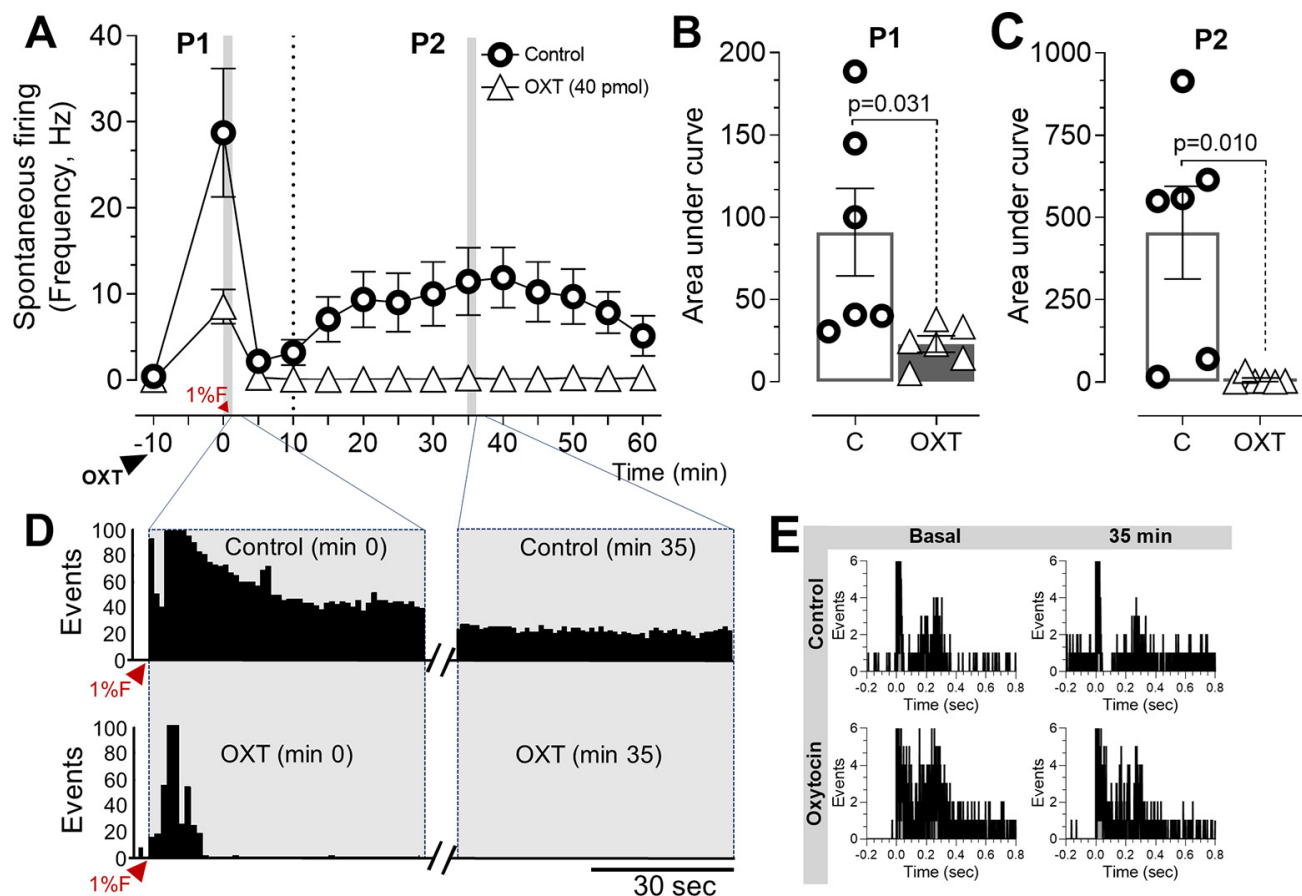

Figure 3. OXT microinjection in the RAIC decreases spinal WDR cell activity on peripheral formalin administration. $A$, Time course of the "spontaneous firing" of spinal WDR cells recorded after OXT microinjection into RAIC $(40 \mathrm{nmol} ; n=6)$ in rats submitted to peripheral subcutaneous $1 \%$ formalin injection. In these electrophysiological experiments, the subcutaneous formalin elicits a biphasic response similar to the one observed in the behavioral experiments, and OXT microinjection successfully diminished the spontaneous firing. $\boldsymbol{B}, \boldsymbol{C}$, The time course data expressed as area under the "spontaneous firing" against time curve (AUC); the unpaired two-tailed $t$ test suggests that OXT reduced the AUC during P1 and P2. For statistical details, see Table 1. D, Time histograms of the WDR spontaneous neuronal activity on peripheral formalin administration at different recording times in both groups: increased neuronal firing of the control neuron at 1 and 35 min after formalin administration compared with a neuron in an animal pretreated with OXT in RAIC under the same experimental conditions. $E$, A PSTH showing the WDR neuronal activity on electrical stimulation of their peripheral RF at 1 and $35 \mathrm{~min}$ after peripheral formalin administration in control (above) and OXT (below) pretreated groups. It is interesting to note that, although the spontaneous firing was drastically diminished in animals treated with OXT, the evoked WDR cell response persisted.
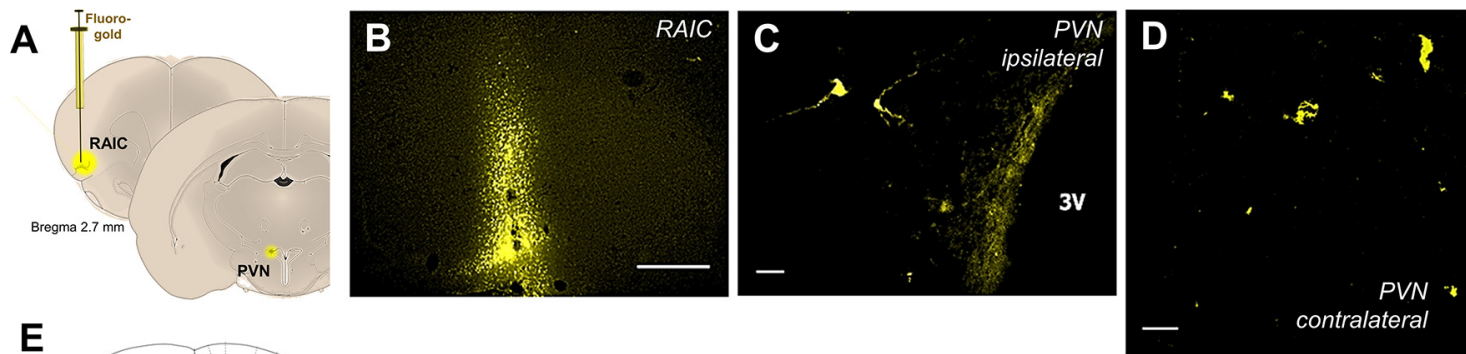

E

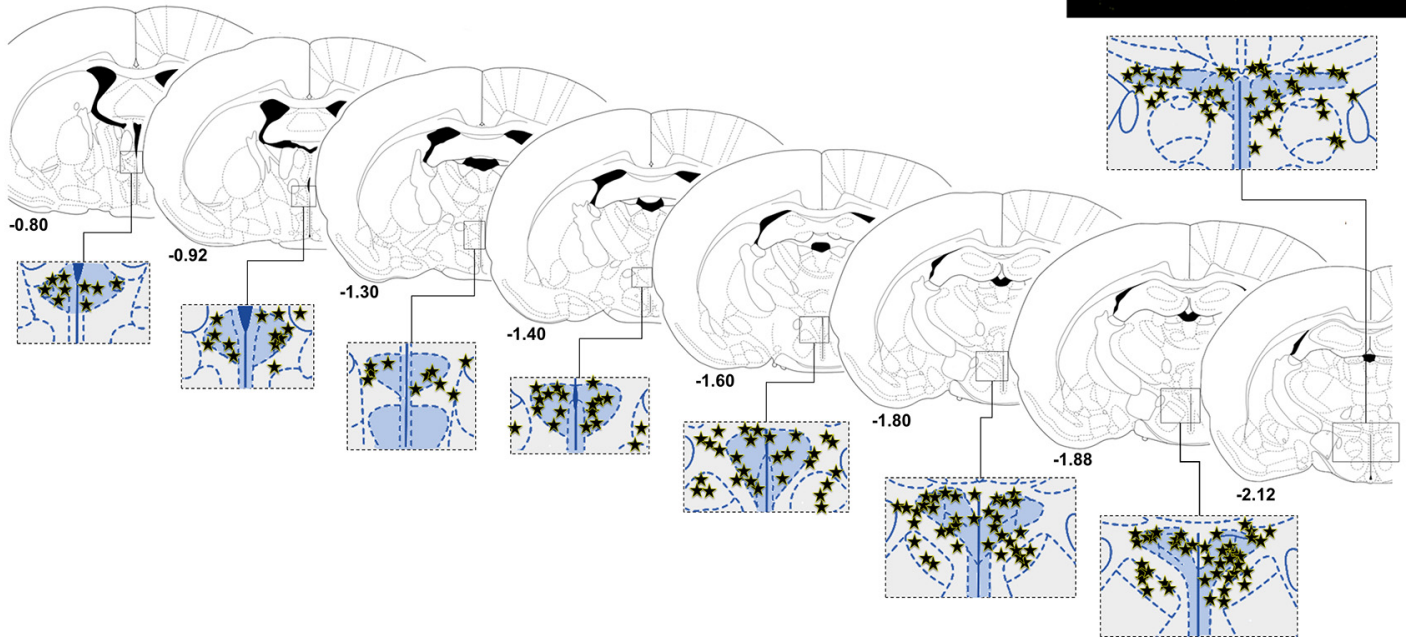

Figure 4. Bilateral PVN projections toward RAIC. $\boldsymbol{A}$, Schematic diagram depicting the PVN with FG-positive cells after injection of this retrograde tracer in the RAIC. $\boldsymbol{B}$, A photomicrograph of the FG injection in the RAIC. Scale bar, $100 \mu \mathrm{m}$. C, D, Photomicrographs showing the presence of bilateral FG-labeled cells inside the PVN. Scale bars: $\boldsymbol{A}, 50 \mu \mathrm{m} ; \boldsymbol{B}, 60 \mu \mathrm{m}$. $\boldsymbol{E}$, Distribution of the FG-labeled cells along the rostrocaudal extension of the PVN. 

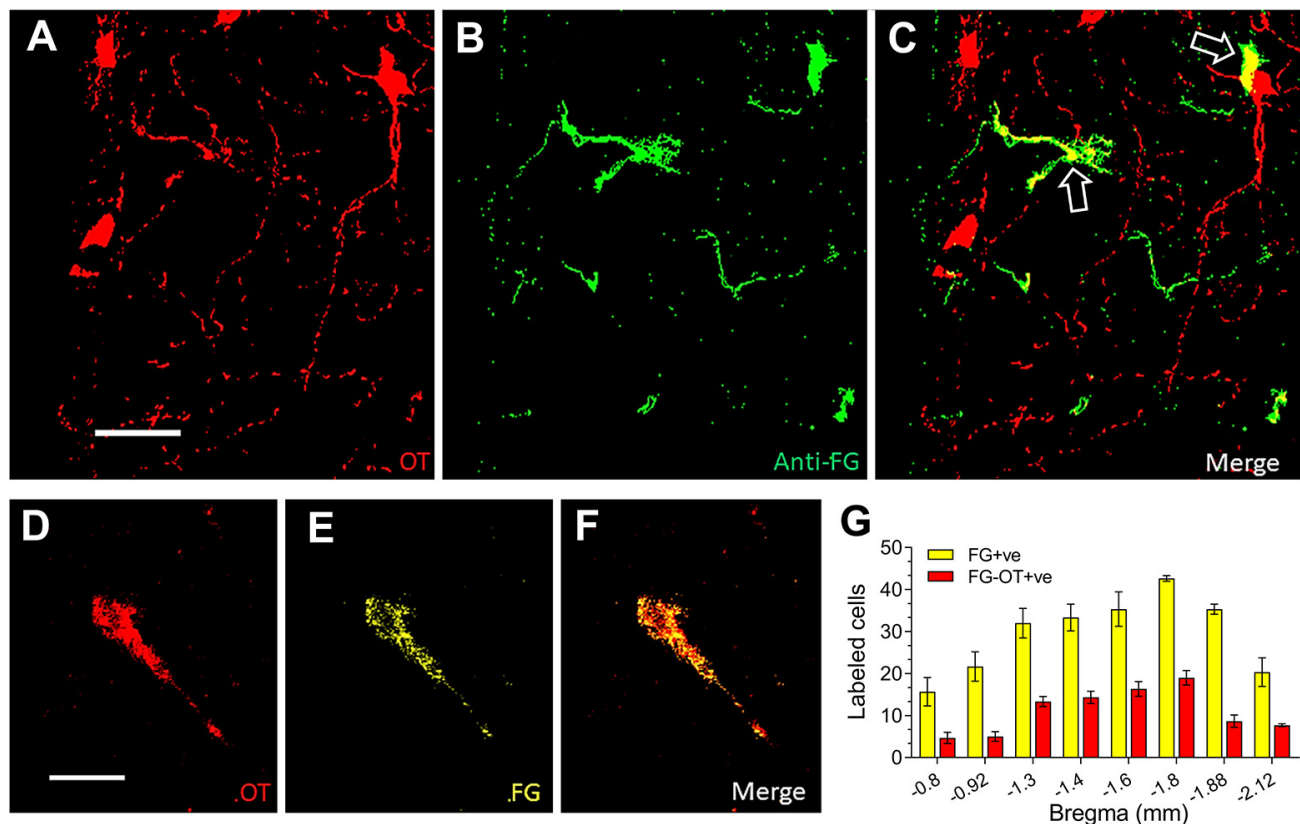

Figure 5. Some PVN-projecting neurons to the RAIC are oxytocinergic. FG was microinjected in the RAIC, and confocal photomicrographs were taken into the PVN demonstrating double-labeled cells. A, OXT-labeled cells (red) in the RAIC. B, Anti-FG-labeled cells (green). C, A merge image (yellow) showing double-labeled cells (white arrows). $\boldsymbol{D}, \boldsymbol{E}$, Photomicrograph exemplifying a PVN cell labeled against OXT (red) and with FG (yellow). $\boldsymbol{F}$, A merge image showing that the cell is double-labeled. Scale bars: $\boldsymbol{A}-\boldsymbol{C}, 50 \mu \mathrm{m} ; \boldsymbol{D}-\boldsymbol{F}, 30 \mu \mathrm{m}$. G, A summary graph showing the rostrocaudal extension of FG-labeled and double-labeled cells along the PVN.

\section{Statistical analysis}

The data analysis was performed using the GraphPad Prism Software (version 8.0). Data are mean \pm SEM. In the case of behavioral and electrophysiological experiments using formalin, curves were constructed by plotting the number of flinches or spontaneous firing as a function of time. The area under the curve (AUC), an expression of the duration and intensity of the effect, was calculated using the trapezoidal rule in which a reduction of the AUC induced by the treatments was considered an antinociceptive effect. In the behavioral experiments, we compared the effect of the different treatments using the one-way ANOVA, whereas for WDR cell recordings we used a nonpaired $t$ test (two-tailed). When we used the one-way ANOVA, we checked the equality of group variances using the Brown-Forsythe test followed by the Tukey post hoc test for multiple comparisons, if applicable. The differences were considered statistically significant when $p<0.05$. The statistical analysis results are detailed in Table 1.

\section{Results}

Oxytocin microinjection into RAIC produces antinociception without motor alterations

The animals pretreated with oxytocin microinjection into RAIC 15-20 min before subcutaneous formalin (5\%) injection (experimental timeline shown in Fig. 1A) showed fewer flinches compared with the control and vehicle groups ( $n=6$ for each group). This effect was remarkable in animals pretreated by a higher concentration of oxytocin ( $400 \mathrm{pmol}, n=6$; Fig. $1 B)$. Upon calculating the AUC, we detected statistical difference between the oxytocin-pretreated groups and the sham and vehicle groups in both phases (P1 and P2) of the formalin test (Fig. 1C,D; Table 1). It is important to remark that, since no statistical difference between sham and vehicle groups was found, we can infer that, under our experimental conditions, the surgical procedure had no relevant impact on the flinching behavior analyzed. Indeed, the number of flinches elicited by $5 \%$ formalin is similar to the one reported by Wheeler-Aceto et al. (1990), who used the same formalin concentration to standardize the formalin test.
Furthermore, to analyze the impact of the craniotomy on locomotor performance, we used the rotarod test. As shown in Figure $1 F$, the surgery impaired the locomotor performance in all groups, but the animals treated with oxytocin seemed less affected (at least statistically). Together, these data only demonstrate that, under our experimental conditions, the impairment of locomotor performance did not affect the flinching behavior.

Since oxytocin microinjection into RAIC diminishes the formalin-induced flinches without impairing the motor coordination, we further explored whether the oxytocin-induced antinociception can be mediated at the spinal pain processing level using an electrophysiological approach.

\section{Oxytocin microinjection into RAIC decreases WDR neuronal firing evoked by peripheral formalin injection} The recorded cells (experimental design shown in Fig. $2 A$ ) were selected based on their somatic responses and classified as WDR cells. This type of cells showed a characteristic response to electrical stimulation, presenting $\mathrm{A} \beta-, \mathrm{A} \delta$-, and C-fiber activity (Fig. $2 B-G$ ). In all cases, these WDR cells did not show spontaneous firing before peripheral formalin administration. Immediately after subcutaneous $1 \%$ formalin injection, an increase in the "spontaneous" WDR cell firing was induced (Fig. 2H,I). The increase in the "spontaneous firing" tailed a similar pattern that we can observe in the case of the formalin test; that is, the neuronal firing showed a biphasic response (Fig. $3 A$ ) correlated with the formalin-induced nociception behavior. This pattern was abolished by RAIC microinjection of oxytocin (40 pmol; Fig. $3 A-C$ ). Figure $3 D$ shows the neuronal firing rate at the first minute and $35 \mathrm{~min}$ after the formalin injection in control animals and animals pretreated with oxytocin. The dramatic decline in "spontaneous" neuronal activity induced by oxytocin was not due to the loss of the recorded cell because, if we applied peripheral electrical stimulation, the characteristic electrophysiological response (as illustrated in Fig. 2E,F) was 

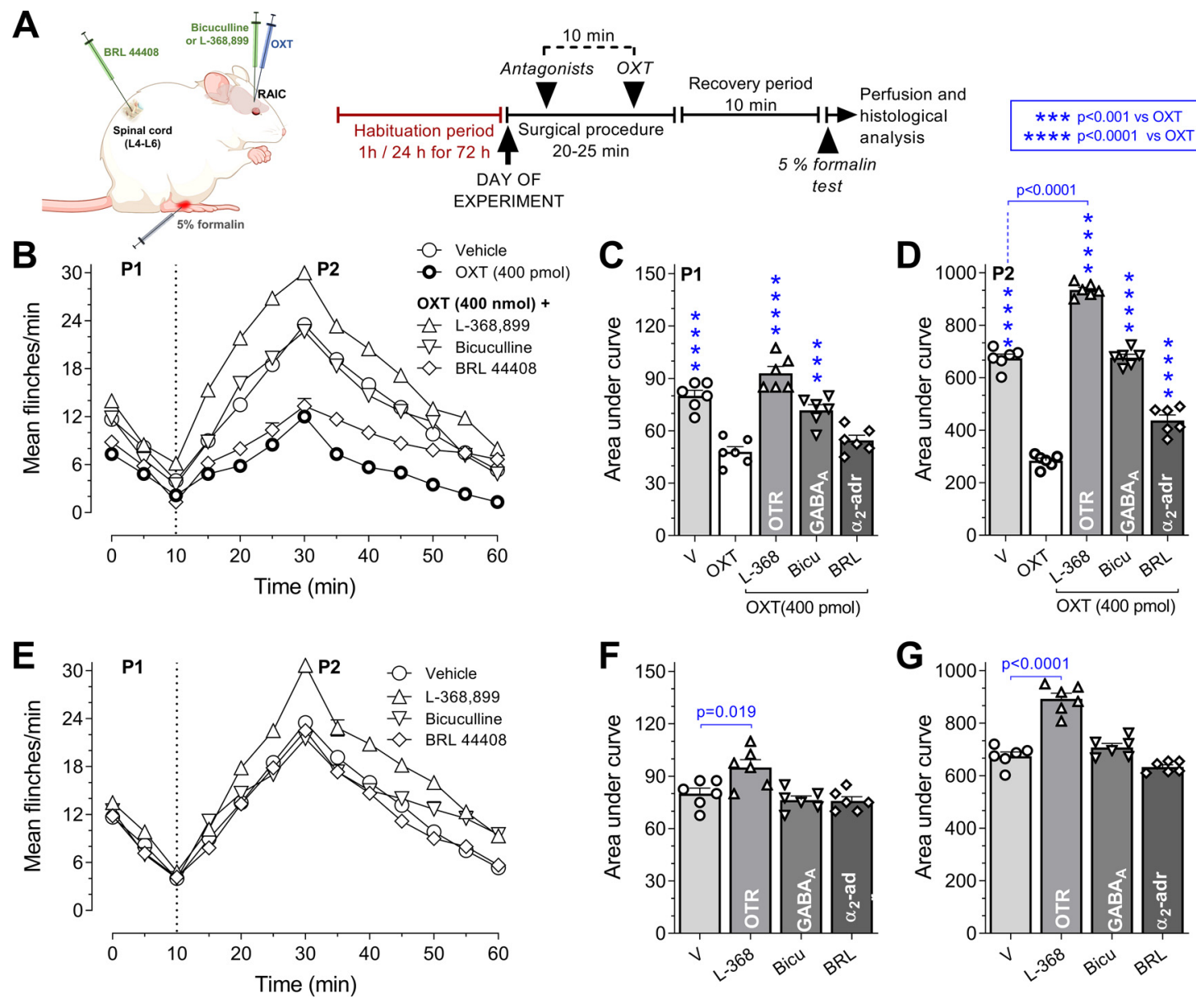

Figure 6. OXT antinociceptive effect in RAIC is mediated by a local OTR and $G A B A_{A}$ activation, which partially promoted a descending noradrenergic modulation. $\boldsymbol{A}$, Diagram and timeline schema of the experimental design used in the 5\% formalin test; OXT, L-368899, and bicuculline were microinjected into RAIC, whereas BRL 44408 was intrathecally delivered. B, Time course during Phase I (P1) and Phase II (P2) of the mean number of flinches observed after treatment with vehicle $(n=6), 0 X T$ administration (400 pmol; $n=6$; showed for comparison), or with: (1) L-368899 (400 pmol; OTR selective antagonist; $n=6$ ) plus OXT, (2) bicuculline (200 pmol; GABA receptor antagonist; $n=6)$ plus OXT, or (3) BRL 44408 ( $\alpha_{2 \mathrm{~A}}$-adrenoceptor antagonist; $1 \mathrm{nmol}$; $n=6$ ) plus OXT, in rats submitted to the formalin test. $C, D$, Data from the time course expressed as area under the mean number of flinches against time curve (AUC). The OXT group represents that of animals receiving an intracortical microinjection of OXT ( $400 \mathrm{pmol}$; shown for comparison). The one-way ANOVA showed differences between treatments, suggesting differences during P1 and P2. While L-368899 and bicuculline abolish the OXT-induced antinociception in both phases, intrathecal BRL 44408 partially reverses the OXT effect only during P2; furthermore, during P2, L-368899 treatment seems to have a pronociceptive effect, considering that it is significantly higher than that observed in the vehicle subgroup. $E-G$, The per se effect of treatment with L-368899, bicuculline, and BRL 44408. L-368899 alone induces a slight (but statistically significant) pronociceptive effect in P1, whereas during P2 the pronociceptive effect is remarkable. For statistical details, see Table 1.

evoked (Fig. 3E). Admittedly, although before formalin administration, we systematically tested (by peripheral electrical stimulation) that the neuron recorded was a WDR cell, we did not systematically perform the electrical stimulation after oxytocin microinjection and thus did not analyze the effect of oxytocin on the peripheral electrical evoked activity.

Considering that microinjection of oxytocin into RAIC not only diminished the nocifensive behavior, but also the formalininduced spontaneous neuronal activity of WDR cells, we further studied the possible source of oxytocin in RAIC by exploring a possible neuroanatomic connection between the PVN and RAIC.

\section{Bilateral PVN oxytocinergic projections to RAIC}

As shown in Figure $4 A$ and $B$, microinjection of FG into RAIClabeling cells bilaterally in the PVN. Considering the size of the labeled cells $(7-20 \mu \mathrm{m})$, most of them can be classified as parvocellular cells. The FG-positive cells were mainly found in the medial part of the PVN (bregma: $-1.4,-1.6 \mathrm{~mm}$ ) or near the third ventricle (Fig. 4C,D), which has been described as a site for parvocellular cell distribution (van den Pol, 1982). Figure $4 E$ shows the distribution of FG-labeled cells along the rostrocaudal extension of the PVN. At this point, we show that a connection between the PVN and RAIC exists, but are these projecting neurons oxytocinergic? To answer this question, we performed the following immunofluorescence experiments.

Immunofluorescence labeling of oxytocinergic cells in the PVN and FG tracer coming from RAIC suggests the projection of oxytocinergic cells from the PVN to RAIC (Fig. $5 A-C$ ). Figure $5 D-F$ clearly exemplifies an FG- and oxytocin-positive cell. A detailed analysis of the double-labeled cells along the PVN rostrocaudal extension is shown in Figure 5G, which displays more oxytocinergic cells projecting to RAIC in the posterior portion of the PVN.

Oxytocin-induced antinociceptive effect in RAIC is mediated by local OTR-GABA $A_{A}$ and spinal $\alpha_{2}$-adrenoceptor mechanisms

Previous studies have described an analgesic effect produced in RAIC by the activation of $\mathrm{GABA}_{\mathrm{A}}$ receptors (Jasmin et al., 2003). 

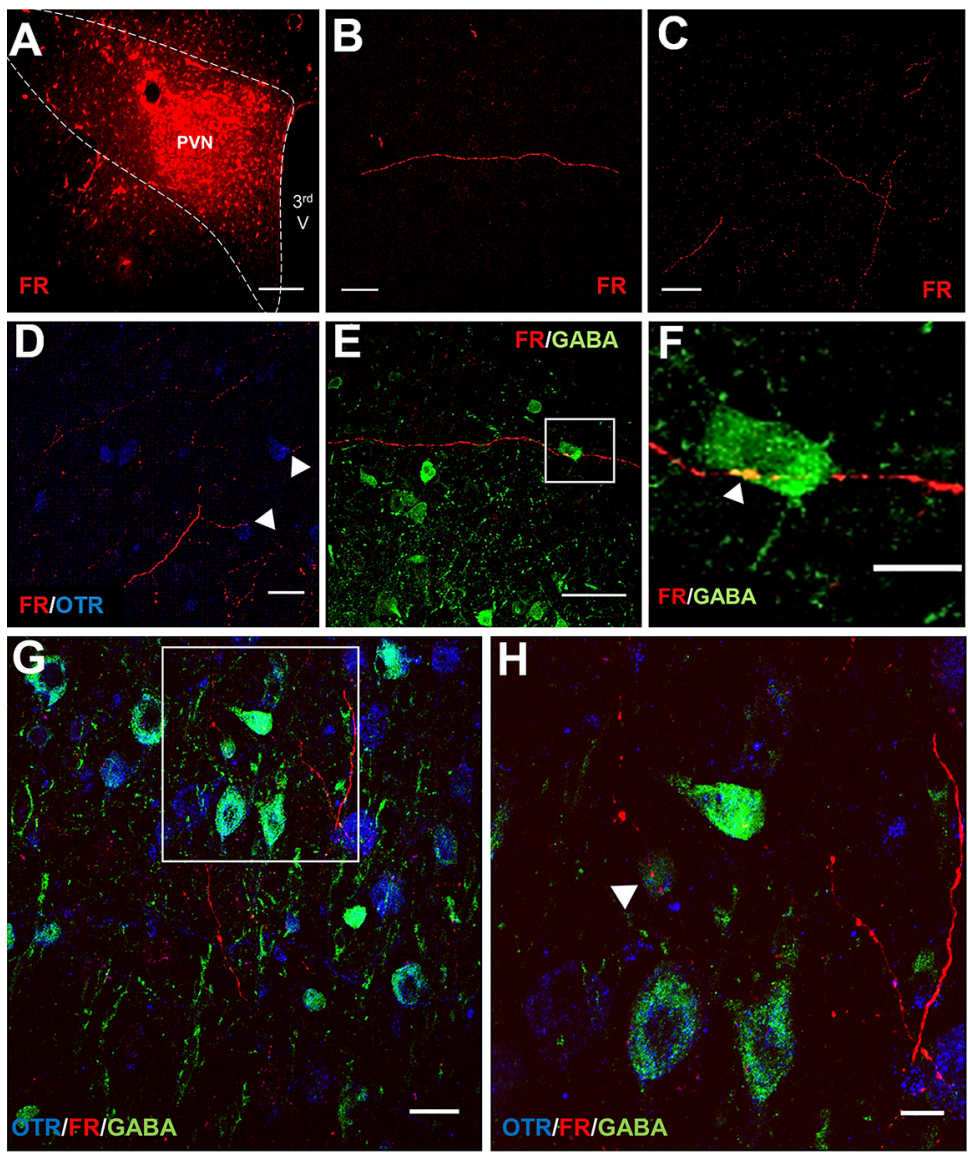

Figure 7. The hypothalamic PVN projections destinate OTR-expressing and GABAergic neurons inside the RAIC. $\boldsymbol{A}$, Photomicrograph of the anterograde tracer FR deposited into the PVN. Scale bar, $120 \mu \mathrm{m}$. $\boldsymbol{B}, \boldsymbol{C}$, Photomicrographs show the presence of FR-labeled fibers inside RAIC. Scale bar: both photomicrographs, $60 \mu \mathrm{m}$. D, A confocal photomicrograph showing the relation between OTR-expressing cells (blue) and FR-labeled fibers (red) inside RAIC. Scale bar, $60 \mu \mathrm{m}$. $\boldsymbol{E}$, A confocal image showing the relation between GABA-labeled cells (green) and FR-labeled fibers (red) inside RAIC. Scale bar, $60 \mu \mathrm{m}$. $\boldsymbol{F}, \mathrm{A}$ crop from $\boldsymbol{E}$ showing the close relation between a GABA-labeled cell (green) and an FR-labeled fiber (red). Scale bar, $30 \mu \mathrm{m}$. G, A representative confocal image showing the relation between OTR-expressing cells (blue), FR-labeled fibers (red), and GABA-labeled neurons (green) inside RAIC. Scale bar, $50 \mu \mathrm{m}$. $\boldsymbol{H}, \mathrm{A}$ cropped image from $\boldsymbol{A}$, showing a single GABA-labeled cell expressing OTR and maintaining a close relation with an FR-labeled fiber (white triangle). Scale bar, $20 \mu \mathrm{m}$.

Hence, we explored whether the oxytocin-induced antinociceptive effect inside RAIC can be mediated by the activation of its receptor (OTR) and by a local $\mathrm{GABA}_{\mathrm{A}}$ receptor mechanism.

Using pharmacological tools and the $5 \%$ formalin test (experimental timeline shown in Fig. 6A), we found that the oxytocininduced antinociception is mediated by its receptor (OTR) and also promotes the following: (1) GABAergic mechanism in RAIC; and (2) $\alpha_{2 \mathrm{~A}}$-adrenoceptor activation at the spinal dorsal horn level (Fig. 6B-D). More specifically, local microinjection of L-368899 (OTR antagonist) or bicuculline (a preferent $\mathrm{GABA}_{\mathrm{A}}$ receptor antagonist) inside RAIC before oxytocin abolished the oxytocin-induced antinociception in both phases of the formalin test. In contrast, intrathecal administration of BRL 44408 ( $\alpha_{2 \mathrm{~A}}$-noradrenergic receptor blocker) only blocked the oxytocin effect in the second phase of the formalin test.

When we analyzed the per se effects induced by the antagonists/blockers, we found that OTR blockade with L-368899, but not bicuculline or BRL 44408, significantly increased the mean number of flinches in the formalin test (Fig. 6E-G). These findings suggest that a tonic oxytocin release into RAIC could exist under an inflammatory pain condition.
PVN projections target GABAergic and OTR-expressing cells inside RAIC

To analyze the relation between the PVN projections to RAIC, OTR-expressing cells, and GABAergic neurons inside this cortex, we performed immunofluorescence experiments. Using an anterograde tracer (FR) injected into the PVN (Fig. $7 A$ ), we observed FR-labeled fibers inside RAIC (Fig. 7B,C). These fibers showed a close relationship with OTR-expressing cells (Fig. 7D) and GABAergic neurons (Fig. $7 E, F$ ). Indeed, as shown in Figure $7 G$ and $H$, we identified GABAergic cells that express OTR and maintain a close relation with FR-labeled fibers. Incubation with only secondary antibodies (negative control) was associated with no fluorescence labeling in all the experiments (data not shown). According to these findings, some PVN projections destinate GABAergic neurons expressing OTR inside RAIC, which endorses a possible local GABAmediated activity that promotes the oxytocin-induced antinociceptive effect in RAIC.

\section{Discussion}

General

Here, and apart from the implications discussed below, we showed that oxytocin microinjection into the rostral portion of the insular cortex (RAIC) induced an antinociceptive effect mediated by the following: (1) a local $\mathrm{GABA}_{\mathrm{A}}$ receptor activation and (2) the recruitment of a descending noradrenergic modulatory mechanism by spinal cord activation of $\alpha_{2 \mathrm{~A}}$-adrenoceptors. Moreover, we described the existence of direct oxytocinergic projections from the PVN (one of the main sites of oxytocin synthesis) toward this cortex, which destinate local GABAergic neurons. A proposed circuit of how oxytocin at RAIC promotes antinociception is depicted in Figure 8.

Oxytocin in RAIC produced antinociception in the presence of inflammatory pain input

As shown in Figure 1, oxytocin microinjection into RAIC decreased the nociceptive effect induced by formalin. Admittedly, under our experimental conditions, we have no direct evidence about the onset of action of oxytocin. Nevertheless, in neuropathic pain models, using behavioral (Eliava et al., 2016; Sun et al., 2018; Taati and Tamaddonfard, 2018; González-Hernández et al., 2019) and electrophysiological approaches (DelaTorre et al., 2009; Eliava et al., 2016), the duration of the antinociceptive effect of central oxytocin ranges between 60 and $90 \mathrm{~min}$, and the onset of the action peaks between 10 and $40 \mathrm{~min}$. In any case, since the $\sim 60 \mathrm{~min}$ formalin-induced nociception is mediated by direct activation of nociceptors (early phase) and inflammatory peripheral process leading to a persistent pain (late phase), it is reasonable to propose that oxytocin in RAIC inhibits the formalin effect by activation of descending 


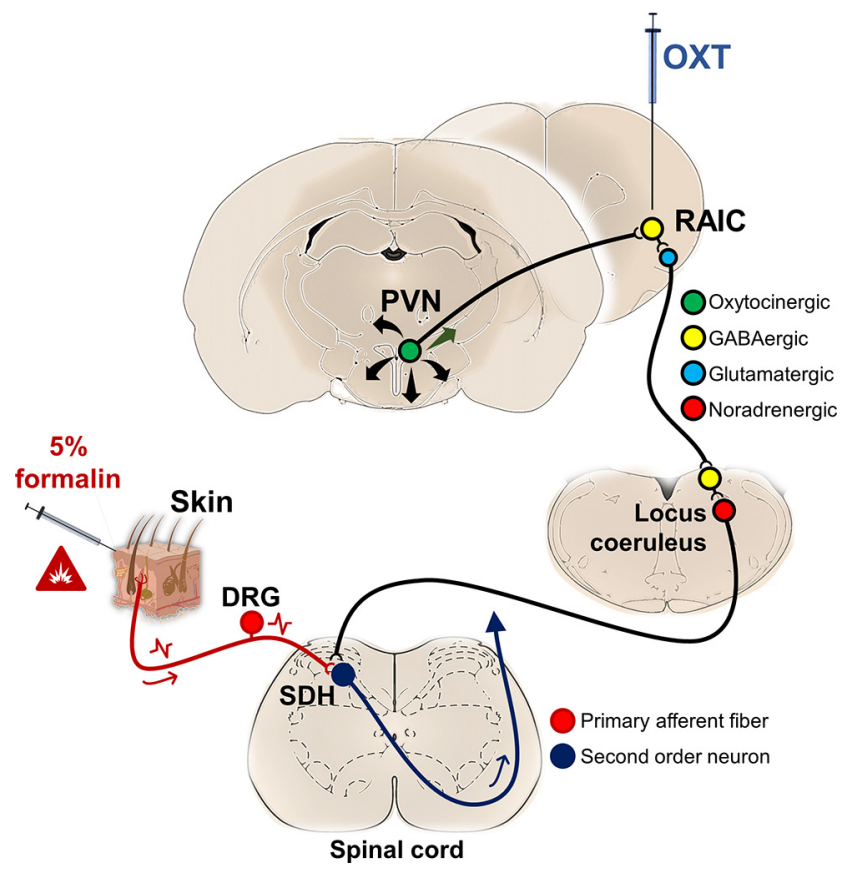

Figure 8. Proposed mechanism for inhibition of pain transmission by OXT in the RAIC. As previously described by Jasmin et al. (2003), glutamatergic fibers from the RAIC target GABAergic cells in the pericerulear region, which inhibit noradrenergic neurons in the $L C$ and consequently diminish the descending inhibition of spinal nociceptive transmission. Here, we show that: (1) some oxytocinergic neurons from the PVN seem to target GABAergic neurons inside the RAIC; and (2) the formalin-induced behavioral and electrophysiological nociception is inhibited by OXT microinjection into the RAIC. Our spinal dorsal horn electrophysiological data showed that microinjection of OXT into the RAIC inhibits pain transmission at the spinal cord level, suggesting a top-down mechanism evoked by this neuropeptide at cortical level. Since intracortical microinjection of the OXT receptor (OTR) antagonist (L-368899) or blockade of $\mathrm{GABA}_{\mathrm{A}}$ channels (using bicuculline) abolished the effect of OXT, a potential GABAergic mechanism enhancing descending antinociception is suggested. Indeed, spinal pretreatment with an $\alpha_{2 \mathrm{~A}}$-adrenoceptor antagonist (BRL 44408) partially blocked the antinociception induced by cortical OXT. Together, our results demonstrate that OXT at the RAIC level could inhibit the nociceptive input at spinal cord level by activating cortical OTR and recruiting GABAergic transmission which, in turn, enhance the spinal $\alpha_{2 A^{-}}$ adrenoceptor activity.

modulatory mechanisms (see below). Direct evidence supporting our contention originates from a previous report showing that, after subcutaneous formalin injection, an increase in the immunoreactivity to oxytocin in the PVN is observed (Motojima et al., 2017). Hence, the notion that under persistent pain input, endogenous oxytocinergic mechanisms are activated to promote endogenous analgesia is supported. Indeed, it is well known that, after PVN stimulation, spinal analgesia by oxytocinergic mechanisms is induced (Condés-Lara et al., 2006; Eliava et al., 2016; Poisbeau et al., 2017).

Since the behavioral experiments were performed after a 10 min recovery from intracortical injection of treatments, a key experiment to exclude any confounding motor effect was the rotarod test (Fig. $1 F$ ). Our results showed that, although after surgery the motor coordination is impaired, oxytocin microinjection improves motor coordination. These results suggest that the oxytocin-induced antinociception is specific and does not rely on a motor deficit. Certainly, we used glass micropipettes ( $\sim 10 \mu \mathrm{m}$ diameter tip) to minimize brain damage and selectively perform a minimal microinjection $(\sim 40 \mathrm{nl})$.

\section{Oxytocin-induced antinociceptive effect implies a descending modulatory mechanism}

Since oxytocin microinjection into RAIC produced a specific behavioral antinociception, we further explored whether this effect could involve nociception modulation at the spinal level like other neuromodulators. For example, Burkey et al. (1996, 1999) showed that microinjections at RAIC of morphine or dopamine induce a descending spinal antinociception; briefly, these compounds reduce the neuronal firing of the nociceptive spinal dorsal horn neurons and diminishes the $c$-fos reactivity induced by peripheral nociceptive stimulus. Thus, we evaluated the effect of oxytocin in RAIC on spinal WDR neuron response on peripheral formalin administration.

The electrical stimulation of the peripheral RF produces a typical well-defined triphasic neuronal-evoked response corresponding to $\mathrm{A} \beta, \mathrm{A} \delta$, and $\mathrm{C}$ fiber activation (Fig. $2 D-F$ ). In this type of spinal second-order neurons, we recorded an increased neuronal firing rate on subcutaneous administration of formalin (Fig. 2H,I). As previously demonstrated (Dickenson and Sullivan, 1987; Haley et al., 1990; Diaz and Dickenson, 1997), subcutaneous formalin injection produced a biphasic neuronal "spontaneous" firing (Fig. $3 A$ ) similar to the one observed in behavioral experiments (Fig. $1 B$ ). Hence, we showed that oxytocin microinjection into RAIC decreased the first phase and second phase of the spontaneous neuronal response (Fig. $3 B-D$ ). Since we found that the WDR response to RF electrical stimulation remains (Fig. 3E), we rule out that the cell recorded was lost. Together, these data support our contention that oxytocin at RAIC promotes a descending antinociceptive mechanism.

\section{PVN oxytocinergic innervations toward RAIC}

Since oxytocin in RAIC produced behavioral and electrophysiological antinociception, we further explored a possible connection between the PVN (a main source of oxytocin) and RAIC. Here, FG microinjection into RAIC-stained cells bilaterally along the rostrocaudal extension of the PVN (Fig. 4). Some of the PVN-projecting neurons toward RAIC were oxytocinergic (Fig. 5); however, some FG-labeled cells were not labeled by oxytocin in PVN. This suggests the presence of other neuromodulators involved in this connection. However, we must admit that, with the tracer technique used, we cannot exclude the possibility that the PVN projections to RAIC reflect fibers of passage. Indeed, as suggested by Chini et al. (2017), hypothalamic oxytocinergic neurons send long axons to several forebrain regions, and these long axons may release (by en passant boutons) oxytocin in more than one area. Certainly, oxytocinergic innervations toward the caudal region of the insular cortex have been described and related with the stress response (Knobloch et al., 2012). In any case, and to the best of our knowledge, we showed that a connection between PVN and RAIC exists.

Considering that: (1) under inflammatory nociceptive stimulus (i.e., peripheral formalin), PVN oxytocinergic transmission is enhanced (Motojima et al., 2017); and (2) at RAIC level, an increased GABAergic activity promotes descending noradrenergic antinociception (Jasmin et al., 2003), we could propose that oxytocin from PVN promotes a descending antinociception by GABAergic transmission.

\section{Oxytocin antinociceptive effect is OTR-GABA $\mathrm{A}_{\mathrm{A}}$-mediated} and involves a descending noradrenergic mechanism Indeed, the oxytocin-induced antinociception in RAIC was mediated by local OTR activity since microinjection of L-368899 (a specific and potent OTR antagonist) (Williams et al., 1994) 
into RAIC before oxytocin abolished this effect (Fig. 6B-D). These results agree with previous studies showing that the insular cortex has OTR binding sites in adult rats (see Gimpl and Fahrenholz, 2001). Furthermore, to test the role of GABAergic mechanisms in the oxytocin-induced antinociception, we showed that bicuculline microinjection before oxytocin abolished its antinociceptive action in the formalin test (Fig. 6). The simplest interpretation of these findings may suggest the role of $\mathrm{GABA}_{\mathrm{A}}$ receptors; however, bicuculline can also block the activity of $\mathrm{K}_{\mathrm{Ca}} 2.1$ and $\mathrm{K}_{\mathrm{Ca}} 2.2$ channels (Strøbaek et al., 2000); consequently, an action on the function of these channels cannot be excluded. Nevertheless, as shown in Figure 7, our immunofluorescence experiments support our contention that oxytocin inhibits nociception by promoting GABAergic neurotransmission. In addition, it is well known that an increase of GABA levels inside RAIC produces antinociception (Jasmin et al., 2003). Furthermore, oxytocin increases local GABA levels in the PFC (Qi et al., 2012).

Since $\mathrm{GABA}_{\mathrm{A}}$ receptor activation in RAIC promotes the recruitment of the descending noradrenergic system (Jasmin et al., 2003), we tested the role of spinal $\alpha_{2 \mathrm{~A}}$-adrenoceptors in the oxytocin effect. Intrathecal administration of BRL 44408 partially reversed the oxytocin-induced behavioral antinociception (Fig. 6). These data suggest that oxytocin-induced antinociception in RAIC is mediated by a local OTR-GABA receptor activation and involves the participation of a descending noradrenergic modulatory mechanism probably promoted by LC disinhibition (Jasmin et al., 2003). However, since the BRL 44408 effect was modest, we could infer that other descending mechanisms or corticocortical interactions are also involved (Ohara et al., 2005; Xie et al., 2009; Chen et al., 2010; Jung et al., 2016; Wu et al., 2016). Indeed, it has been shown that PVN electrical stimulation enhances c-fos expression not only in LC but also in the RM and PAG (Condés-Lara et al., 2015), both structures related with descending pain inhibition by serotonergic and opioidergic transmission.

One interesting finding was that microinjection of L-368899 per se in RAIC produced a pronociceptive effect (Fig. $6 E-G$ ), suggesting the existence of a tonic endogenous oxytocin release in RAIC during inflammatory nociception. Accordingly, Motojima et al. (2017) showed that peripheral formalin elicited an increase of the PVN oxytocinergic activity, supporting the role of the PVN oxytocinergic system modulating inflammatory nociceptive input. In contrast, as previously reported by Jasmin et al. (2003), when we evaluated the per se effect induced by bicuculline, we did not find any effect on the nociceptive responses elicited by formalin. These findings suggest that, although $\mathrm{GABA}_{\mathrm{A}}$-related mechanisms at RAIC are relevant for the oxytocin actions, other OTR-dependent mechanisms are also elicited by this neuropeptide.

\section{Further anatomic evidence supporting the role of OTR and GABAergic mechanisms in the intracortical oxytocin effect} The fact that PVN projections target GABAergic neurons and OTR-expressing cells inside RAIC (Fig. 7) supports the notion that oxytocin antinociceptive effect elicited in the behavioral and electrophysiological experiments could be mediated by local OTR and GABAergic neurotransmission. Nevertheless, as discussed above, we cannot exclude the possible coinvolvement of other mechanisms.

In conclusion, since a PVN oxytocinergic neuronal projection to RAIC exists and oxytocin in RAIC produced an antinociceptive effect, we suggest that RAIC is a site of oxytocin-induced analgesia. Indeed, the antinociceptive effect induced by intracortical injection of oxytocin seems to be mediated by a local cortical OTR-GABA $A_{\mathrm{A}}$ activity that partially promotes a descending spinal noradrenergic mechanism. Furthermore, our results suggest a possible tonic release of oxytocin in RAIC during inflammatory pain input.

\section{References}

Burkey AR, Carstens E, Jasmin L (1999) Dopamine reuptake inhibition in the rostral agranular insular cortex produces antinociception. J Neurosci 19:4169-4179.

Burkey AR, Carstens E, Wenniger JJ, Tang J, Jasmin L (1996) An opioidergic cortical antinociception triggering site in the agranular insular cortex of the rat that contributes to morphine antinociception. J Neurosci $16: 6612-6623$.

Chen YL, Li AH, Yeh TH, Chou AH, Weng YS, Wang HL (2010) Nocistatin excites rostral agranular insular cortex-periaqueductal gray projection neurons by enhancing transient receptor potential cation conductance via G $\alpha \mathrm{q} / 11$-PLC-protein kinase C pathway. Neuroscience 168:226-239.

Chini B, Verhage M, Grinevich V (2017) The Action Radius of Oxytocin Release in the Mammalian CNS: From Single Vesicles to Behavior. Trends Pharmacol Sci 38:982-991.

Coffeen U, Manuel Ortega-Legaspi J, López-Muñoz FJ, Simón-Arceo K, Jaimes O, Pellicer F (2011) Insular cortex lesion diminishes neuropathic and inflammatory pain-like behaviours. Eur J Pain 15:132-138.

Condés-Lara M, Rojas-Piloni G, Martínez-Lorenzana G, Rodríguez-Jiménez J, López Hidalgo M, Freund-Mercier MJ (2006) Paraventricular hypothalamic influences on spinal nociceptive processing. Brain Res 1081:126-137.

Condés-Lara M, Rojas-Piloni G, Martínez-Lorenzana G, Rodríguez-Jiménez J (2009) Paraventricular hypothalamic oxytocinergic cells responding to noxious stimulation and projecting to the spinal dorsal horn represent a homeostatic analgesic mechanism. Eur J Neurosci 30:1056-1063.

Condés-Lara M, Rojas-Piloni G, Martínez-Lorenzana G, Diez-Martínez DC, Rodríguez-Jiménez J (2012) Functional interactions between the paraventricular hypothalamic nucleus and raphe magnus. A comparative study of an integrated homeostatic analgesic mechanism. Neuroscience 209:196-207.

Condés-Lara M, Martínez-Lorenzana G, Rubio-Beltrán E, RodríguezJiménez J, Rojas-Piloni G, González-Hernández A (2015) Hypothalamic paraventricular nucleus stimulation enhances c-Fos expression in spinal and supraspinal structures related to pain modulation. Neurosci Res 98:59-63.

DeLaTorre S, Rojas-Piloni G, Martínez-Lorenzana G, Rodríguez-Jiménez J, Villanueva L, Condés-Lara M (2009) Paraventricular oxytocinergic hypothalamic prevention or interruption of long-term potentiation in dorsal horn nociceptive neurons: electrophysiological and behavioral evidence. Pain 144:320-328.

Diaz A, Dickenson AH (1997) Blockade of spinal N- and P-type, but not Ltype, calcium channels inhibits the excitability of rat dorsal horn neurons produced by subcutaneous formalin inflammation. Pain 69:93-100.

Dickenson AH, Sullivan AF (1987) Subcutaneous formalin-induced activity of dorsal horn neurons in the rat: differential response to an intrathecal opiate administered pre or post formalin. Pain 30:349-360.

Dubuisson D, Dennis SG (1977) The formalin test: a quantitative study of the analgesic effects of morphine, meperidine, and brain stem stimulation in rats and cats. Pain 4:161-174.

Dumais KM, Veenema AH (2016) Vasopressin and oxytocin receptor systems in the brain: sex differences and sex-specific regulation of social behavior. Front Neuroendocrinol 40:1-23.

Eliava M, Melchior M, Knobloch-Bollmann HS, Wahis J, da Silva Gouveia M, Tang Y, Ciobanu AC, Triana Del Rio R, Roth LC, Althammer F, Chavant V, Goumon Y, Gruber T, Petit-Demoulière N, Busnelli M, Chini B, Tan LL, Mitre M, Froemke RC, Chao MV, et al. (2016) A new population of parvocellular oxytocin neurons controlling magnocellular neuron activity and inflammatory pain processing. Neuron 89:12911304.

Gamal-Eltrabily M, de los Monteros-Zúñiga AE, Martínez-Lorenzana G, González-Hernández A (2019) PVN oxytocinergic projections to the rostral agranular insular cortex and the possible role in nociception. J Neurochem 150:165. 
Gimpl G, Fahrenholz F (2001) The oxytocin receptor system: structure, function, and regulation. Physiol Rev 81:629-683.

Godínez-Chaparro B, Martínez-Lorenzana G, Rodríguez-Jiménez J, Manzano-García A, Rojas-Piloni G, Condés-Lara M, GonzálezHernández A (2016) The potential role of serotonergic mechanisms in the spinal oxytocin-induced antinociception. Neuropeptides 60:51-60.

Gonzalez-Hernandez A, Charlet A (2018) Oxytocin, GABA, and TRPV1, the analgesic triad? Front Mol Neurosci 11:398.

González-Hernández A, Rojas-Piloni G, Condés-Lara M (2014) Oxytocin and analgesia: future trends. Trends Pharmacol Sci 35:549-551.

González-Hernández A, Espinosa De Los Monteros-Zuñiga A, MartínezLorenzana G, Condés-Lara M (2019) Recurrent antinociception induced by intrathecal or peripheral oxytocin in a neuropathic pain rat model. Exp Brain Res 237:2995-3010.

Haley J, Ketchum S, Dickenson A (1990) Peripheral $\kappa$-opioid modulation of the formalin response: an electrophysiological study in the rat. Eur J Pain 191:437-446.

Jasmin L, Rabkin SD, Granato A, Boudah A, Ohara PT (2003) Analgesia and hyperalgesia from GABA-mediated modulation of the cerebral cortex. Nature 424:316-320.

Jasmin L, Burkey AR, Granato A, Ohara PT (2004) Rostral agranular insular cortex and pain areas of the central nervous system: a tract-tracing study in the rat. J Comp Neurol 468:425-440.

Jung HH, Shin J, Kim J, Ahn SH, Lee SE, Koh CS, Cho JS, Kong C, Shin HC, Kim SJ, Chang JW (2016) Rostral agranular insular cortex lesion with motor cortex stimulation enhances pain modulation effect on neuropathic pain model. Neural Plast 2016:3898924.

Kaneko Y, Pappas C, Tajiri N, Borlongan CV (2016) Oxytocin modulates $\mathrm{GABA}_{\mathrm{A}} \mathrm{R}$ subunit to confer neuroprotection in stroke in vitro. Sci Rep 6:356-359.

Knobloch HS, Charlet A, Hoffmann LC, Eliava M, Khrulev S, Cetin AH, Osten P, Schwarz MK, Seeburg PH, Stoop R, Grinevich V (2012) Evoked axonal oxytocin release in the central amygdala attenuates fear response. Neuron 73:553-566.

Madrazo I, Franco-Bourland RE, León-Meza V, Mena I (1987) Intraventricular somatostatin-14, arginine vasopressin, and oxytocin: analgesic effect in a patient with intractable cancer pain. Appl Neurophysiol 50:427-431.

McGrath J, Drummond G, McLachlan E, Kilkenny C, Wainwright C (2010) Guidelines for reporting experiments involving animals: the ARRIVE guidelines. Br J Pharmacol 160:1573-1576.

Mestre C, Pélissier T, Fialip J, Wilcox G, Eschalier A (1994) A method to perform direct transcutaneous intrathecal injection in rats. J Pharmacol Methods 32:197-200.

Miranda-Cardenas Y, Rojas-Piloni G, Martínez-Lorenzana G, RodríguezJiménez J, López-Hidalgo M, Freund-Mercier MJ, Condés-Lara M (2006) Oxytocin and electrical stimulation of the paraventricular hypothalamic nucleus produce antinociceptive effects that are reversed by an oxytocin antagonist. Pain 122:182-189.

Moghadam SE, Tameh AA, Vahidinia Z, Atlasi MA, Bafrani HH, Naderian $H$ (2018) Neuroprotective effects of oxytocin hormone after an experimental stroke model and the possible role of calpain-1. J Stroke Cerebrovasc Dis 27:724-732.

Motojima Y, Matsuura T, Yoshimura M, Hashimoto H, Saito R, Ueno H, Maruyama T, Sonoda S, Suzuki H, Kawasaki M, Ohnishi H, Sakai A,
Ueta Y (2017) Comparison of the induction of c-fos-eGFP and Fos protein in the rat spinal cord and hypothalamus resulting from subcutaneous capsaicin or formalin injection. Neuroscience 356:64-77.

Ohara PT, Vit JP, Jasmin L (2005) Cortical modulation of pain. Cell Mol Life Sci 62:44-52.

Paxinos G, Watson C (2006) The rat brain in stereotaxic coordinates Amsterdam: Elsevier.

Pittman QJ, Blume HW, Renaud LP (1981) Connections of the hypothalamic paraventricular nucleus with the neurohypophysis, median eminence, amygdala, lateral septum and midbrain periaqueductal gray: an electrophysiological study in the rat. Brain Res 215:15-28.

Poisbeau P, Grinevich V, Charlet A (2017) Oxytocin signaling in pain: cellular, circuit, system, and behavioral levels. In: Behavioral pharmacology of neuropeptides: oxytocin, pp 193-211. New York: Springer.

Qi J, Han WY, Yang JY, Wang LH, Dong YX, Wang F, Song M, Wu CF (2012) Oxytocin regulates changes of extracellular glutamate and GABA levels induced by methamphetamine in the mouse brain. Addict Biol 17:758-769.

Sabihi S, Dong SM, Maurer SD, Post C, Leuner B (2017) Oxytocin in the medial prefrontal cortex attenuates anxiety: anatomical and receptor specificity and mechanism of action. Neuropharmacology 125:1-12.

Strøbaek D, Jørgensen TD, Christophersen P, Ahring PK, Olesen SP (2000) Pharmacological characterization of small-conductance $\mathrm{Ca}(2+)$-activated $\mathrm{K}(+)$ channels stably expressed in HEK 293 cells. Br J Pharmacol 129:991-999.

Sun W, Zhou Q, Ba X, Feng X, Hu X, Cheng X, Liu T, Xiao L, Jiang J, Xiong D, Hao Y, Chen Z, Xiong D (2018) Oxytocin relieves neuropathic pain through GABA release and presynaptic TRPV1 inhibition in spinal cord. Front Mol Neurosci 11:248.

Taati M, Tamaddonfard E (2018) Ventrolateral orbital cortex oxytocin attenuates neuropathic pain through periaqueductal gray opioid receptor. Pharmacol Rep 70:577-583.

Thakur P, Shrivastava R, Shrivastava VK (2019) Effects of exogenous oxytocin and atosiban antagonist on GABA in different region of brain. IBRO Rep 6:185-189.

van den Pol AN (1982) The magnocellular and parvocellular paraventricular nucleus of rat: intrinsic organization. J Comp Neurol 206:317-345.

Wheeler-Aceto H, Porreca F, Cowan A (1990) The rat paw formalin test: comparison of noxious agents. Pain 40:229-238.

Williams PD, Anderson PS, Ball RG, Bock MG, Carroll L, Chiu SH, Clineschmidt BV, Culberson JC, Erb JM, Evans BE, Fitzpatrick SL, Freidinger RM, Kaufman MJ, Lundell GF, Murphy JS, Thompson KL, Veber DF (1994) 1-((7,7-Dimethyl-2(S)-(2(S)-amino-4-(methylsulfonyl) butyramido)bicyclo [2.2.1]-heptan-1(S)-yl)methyl)sulfonyl)-4-(2-methylphenyl)piperazine (L-368,899): an orally bioavailable, non-peptide oxytocin antagonist with potential utility for managing preterm labor. J Med Chem 37:565-571.

Wu WY, Liu CY, Tsai ML, Yen CT (2016) Nocifensive behavior-related laser heat-evoked component in the rostral agranular insular cortex revealed using morphine analgesia. Physiol Behav 154:129-134.

Xie YF, Huo FQ, Tang JS (2009) Cerebral cortex modulation of pain. Acta Pharmacol Sin 30:31-41.

Yoon MH, Huang LJ, Choi JI, Lee HG, Kim WM, Kim CM (2011) Antinociceptive effect of intrathecal ginsenosides through $\alpha-2$ adrenoceptors in the formalin test of rats. Br J Anaesth 106:371-379. 